\title{
Code status communication training in postgraduate oncology programs: a needs assessment
}

\author{
O.H. Levine MD, ${ }^{*}$ S.K. Dhesy-Thind MD, ${ }^{*}$ M.M. McConnell PhD, ${ }^{\dagger \neq}$ M.C. Brouwers PhD, \\ and S.D. Mukherjee MD*
}

\begin{abstract}
Background Discussions with patients with cancer about cardiopulmonary resuscitation directives (code status) are often led by residents. This study was carried out in Canada to identify current educational practices and gaps in training for this communication skill.
\end{abstract}

Methods Canadian medical and radiation oncology residents and program directors (PDs) were surveyed about teaching practices, satisfaction with current education, and barriers to teaching code status discussion skills. Relative frequencies of categorical and ordinal responses were calculated.

Results Between November 2016 and February 2017, 95 (58.6\%) of 162 residents and 17 (63\%) of 27 PDs completed surveys. Only $54.1 \%$ and $48.3 \%$ of medical and radiation oncology residents, respectively, had received any code status communication training before entering an oncology program. While $41 \%$ of residents expected to receive formal teaching on this topic during residency, $47.1 \%$ of PDs endorsed inclusion of this topic in curricula. Only $20 \%$ of residents reported receiving formal evaluation of this skill while $41.2 \%$ of PDs indicated that evaluations are provided. The importance of this communication skill in oncology was strongly supported. Among residents, $88 \%$ desired more training, and $82.3 \%$ of PDs identified the need for new educational resources. Lack of time, resources, and evaluation tools were among the most commonly identified barriers to teaching.

Conclusions Oncology residency PDs and trainees feel that code status communication is important, but teaching and evaluation of this skill are limited. Barriers to teaching and skill-building have been identified. Further work is underway to develop novel educational resources for code status communication training.

Key Words Postgraduate medical education, advanced directives

Curr Oncol. 2020 December:27(6)e607-e613

www.current-oncology.com

\section{BACKGROUND}

Despite therapeutic advances, cancer remains a terminal illness for many patients. Thus, quality end-of-life (EOL) care is an essential component of the cancer care continuum. Oncologists participate in EOL care and have to be proficient in communicating about cardiopulmonary resuscitation preferences, also known as "code status." Code status conversations are frequently the responsibility of residents at the time of patient hospitalization ${ }^{1}$. However, residents often feel unprepared to lead such discussions ${ }^{2,3}$. They may follow a depersonalized, formulaic approach to elicit a patient's preferences regarding cardiopulmonary resuscitation ${ }^{4}$, often fail to provide necessary information such as likely outcomes of cardiopulmonary resuscitation, and tend not to give a medical recommendation ${ }^{5}$. Failure to provide appropriate code status communication substantially affects patient care, because patients and providers might not share the same understanding of a decision for or against life-sustaining interventions ${ }^{5,6}$. Thus, skill-building for code status communication is an important objective in postgraduate oncology training.

Formal and informal teaching can improve the quality of code status conversations led by residents. Supervision 
and feedback increase the rate at which residents include key content, such as exploration of patient values, in EOL care decision-making ${ }^{1}$. Communication training retreats and workshops have yielded improvements in quality of communication by residents in simulated patient encounters $^{7-9}$. Yet existing educational programs (for example, a multiday retreat) are generally complex and resource-intensive, limiting uptake across programs ${ }^{9}$. As a result, structured teaching of communication skills for code status discussion is not standardized across oncology training programs. While some residents might have received training on these discussions before entering an oncology program, conversations with patients with cancer are influenced by understanding prognosis and treatment options, and require enhanced communication skills.

In this study, a systematic assessment of current and desired training activities for this communication skill was carried out. The objectives were to define current teaching practices in Canadian oncology training programs and to identify whether residents and program directors (PDs) perceive a need for new educational resources relating to code status discussions.

\section{METHODS}

\section{Study Design and Population}

This cross-sectional study involved a survey distributed between November 2016 and January 2017 to all enrolled residents and PDs in medical oncology and radiation oncology training programs in Canada. This study received approval after full review by the Hamilton Integrated Research Ethics Board affiliated with McMaster University (project no. 2376).

Medical oncology residency is a 2-year training program that commences in the 4 th postgraduate year, after the completion of 3 years of internal medicine training and 3-4 years of undergraduate medical education. Radiation oncology is a 5-year, direct-entry residency program after medical school. There are 15 and 13 accredited medical and radiation oncology residency programs, respectively, in Canada, and 162 residents were in one or the other of these training programs at the time of survey distribution.

\section{Survey Development}

Two surveys were developed and piloted at McMaster University: one targeted to PDs and the other developed for residents. The overall aim was to quantify current teaching about code status communication. No existing survey tool was identified in the literature, and so novel study instruments were developed following a rigorous process. Initial survey items were developed by a study investigator (OHL) to capture demographics, current educational activities, perceived gaps in residency training pertaining to code status communication, attitudes toward this communication skill, and barriers to education on this topic. We also aimed to capture current patterns of practice for code status discussions to identify whether real-world clinical encounters could serve as learning opportunities. Response options were mostly categorical (yes/ no, or checklists), with the opportunity to add comments.
Some items involved 7-point Likert scales with adjectival anchors (ranging from strongly disagree to strongly agree).

Following standards for measurement design ${ }^{10}$, item generation was informed by literature review and expert consultation. Previously published studies have addressed some of the domains of interest, and so items were adapted from available tools where possible. For example, selfefficacy among residents regarding code status communication has previously been measured on a 5-point Likert scale $^{11}$. We opted to use a 7-point scale for possible improved discriminating power ${ }^{10,12}$. We asked about barriers to education and barriers to resident-led code status communication, with checklist response options that included established barriers from the literature (for example, lack of time and lack of rapport with a patient ${ }^{13}$. We adapted items to address frequency of resident-led code status discussions and provision of a code status recommendation in such discussions ${ }^{13}$. We expanded upon published survey items to assess the clinical environment in which conversations occur. In an iterative process, the survey instruments were revised by senior investigators (MCB, MMM) with extensive experience in psychometrics, measurement, and survey design.

Tools were piloted to assess content and face validity. The pilot group of 10 individuals included trainees, former PDs, and faculty educators in medical and radiation oncology at McMaster University. Fellows (recent graduates from oncology residency programs pursuing further subspecialty training) and graduating residents were asked to complete the surveys to avoid overlap between the pilot group and the final study population. Feedback about the comprehensiveness, content relevance, and clarity of the survey was sought and modifications made in response. The final survey instruments are available in the supplementary material.

\section{Data Collection}

Final surveys were distributed, and recipients had 30 days to submit responses. All responses were collected confidentially. Surveys were sent electronically to 27 PDs (14 medical oncology and 13 radiation oncology-1 PD was not contacted due to a transition of leadership coinciding with the study) using the Lime Survey software (LimeSurvey, Hamburg, Germany). Residents from 6 training programs in Ontario received paper-based surveys while participating in an educational workshop unrelated to this study. The remaining residents received the survey electronically with a generic link so responders were not tracked. Invitation messages were distributed by e-mail through program administrators for all Canadian oncology training programs. Additionally, administrators were asked to send a reminder e-mail message 1 week before the end of the response period. To protect privacy, study personnel were not provided with trainees' contact information or the distribution lists. Accordingly, the total study population was estimated from the Canadian Residency Matching Service (CaRMS) recent match results indicating the number of residents entering postgraduate training programs in Canada each year $^{14,15}$. An estimated 162 residents received surveys. A \$5 coffee card was offered to residents as a token incentive to encourage participation. 


\section{Analysis}

Relative frequencies of categorical and ordinal responses were calculated. Descriptive statistics were generated with Microsoft Excel software (Microsoft Corporation, Redmond, WA, U.S.A.). To probe the influence of prior internal medicine training for medical oncology residents, we compared responses by discipline (medical versus radiation oncology) and by level of training (junior versus senior residents). "Junior residents" comprised postgraduate year 1-3 radiation oncology trainees; "senior residents" included postgraduate year 4-5 trainees from both disciplines. The chi-square test was used to examine difference in proportions in the IBM SPSS Statistics software application (IBM, Armonk, NY, U.S.A.). In the event of low expected cell count in a contingency table, the Fisher exact test was used.

\section{RESULTS}

\section{Response Rate and Demographic Characteristics}

A total of 112 survey responses were collected, 17 from PDs (63.0\% response rate) and 95 from residents $(58.6 \%$ response rate). Response rates were similar across oncology disciplines, and trainees from all postgraduate years were well represented (Table I).

\section{Environmental Scan of Current Educational Practices}

Responses about current educational practices for code status communication are summarized in Table II. Regarding baseline level of training, only $54.1 \%$ and $48.3 \%$ of medical oncology and radiation oncology residents, respectively, reported any form of code status communication training before entering an oncology program. Medical oncology residents reported prior training mostly during internal medicine residency, whereas radiation oncology residents reported experiences in medical school. Less than half $-43.2 \%$ and $48.3 \%$, respectively, of medical oncology and radiation oncology residents-reported perceiving an expectation of competence in this communication skill before starting oncology training. More medical oncology PDs than radiation oncology $\mathrm{PDs}$ reported an expectation that trainees be competent in this area before program entry, although this difference was not statistically significant (55.6\% vs. $37.5 \%, p=0.64$ ). Medical oncology PDs commonly stated an expectation that residents receive prior training during internal medicine residency. For example, "Code status discussions are a core competency that precedes entry into postgraduate year 4 . It is repeated regularly during internal medicine, and usually it is the seniors who instill the culture of establishing code status to the juniors."

Although radiation oncology residents do not have prior postgraduate training, some radiation oncology PDs expressed that training on code status discussion occurs in other clinical environments: "There is an expectation that teaching and assessment of code status occurs on off-service inpatient rotations (particularly internal medicine and $\mathrm{CCU}) . "$

Regarding current educational practices within oncology residency programs, $47.1 \%$ of PDs reported that formal
TABLE I Characteristics of respondents

\begin{tabular}{cccc}
\hline \multirow{2}{*}{ Participant type } & \multicolumn{3}{c}{ Response rate by discipline $[\boldsymbol{n}(\%)]$} \\
\cline { 2 - 4 } & Overall & $\begin{array}{c}\text { Medical } \\
\text { oncology }\end{array}$ & $\begin{array}{c}\text { Radiation } \\
\text { oncology }\end{array}$ \\
\hline Program directors & $17(63.0)$ & $9(64.3)$ & $8(61.5)$ \\
Residents & $95(58.6)$ & $37(59.7)$ & $58(58.0)$ \\
PGY1 & 11 & - & 11 \\
PGY2 & 15 & - & 15 \\
PGY3 & 9 & - & 9 \\
PGY4 & 34 & 19 & 15 \\
PGY5 & 26 & 18 & 8 \\
\hline
\end{tabular}

a Training starts in the 4th postgraduate year.

$\mathrm{PGY}=$ postgraduate year.

training on code status was provided to oncology residents, and $41.1 \%$ of trainees anticipated this type of education would be offered by the end of residency (Figure 1). More than one quarter of trainees were not sure whether their programs provided this training. Formal training was expected more commonly among medical oncology residents than radiation oncology residents $(54.1 \%$ vs. $32.8 \%$, $p=0.01$ ). Educational formats most commonly identified included structured academic sessions (didactic or casebased teaching) and mandatory observation and feedback in the ambulatory care setting. Informal training on this topic was reported more commonly, with most (82.3\%) PDs endorsing current teaching through non-mandated observation and feedback in a variety of patient-care settings.

When asked about formal evaluation of code status communication, only $41.2 \%$ of PDs and $20 \%$ of residents reported that evaluation of this skill is currently provided to trainees. Identified methods of evaluation were observed structured clinical examinations and in-training evaluation reports. Few PDs reported mechanisms in place to identify weakness in this skill among learners (29.4\%) or to offer remediation for trainees not meeting expectations in this area $(35.3 \%)$.

\section{Perceived Importance of Code Status Communication Skills}

All PDs positively endorsed the importance of this communication skill both in residency and in clinical practice, with most participants (70.6\%) "strongly agreeing" with its importance in both contexts. Similarly, among residents, $97.9 \%$ and $98.9 \%$ positively endorsed the importance of this skill in residency and in clinical practice, respectively.

\section{Satisfaction Among Trainees with Current Teaching}

Only $36.8 \%$ of residents indicated satisfaction with current training on the topic of code status discussions. The rate of satisfaction was higher among medical oncology residents than radiation oncology residents ( $45.9 \%$ vs. $31 \%$ ), although this difference was not significant $(p=0.14)$. Moreover, $85.2 \%$ of residents agreed at some level that additional training would be of benefit, with no difference seen between medical and radiation oncology residents $(83.8 \%$ vs. $86.2 \%, p=0.75$ ), or between junior and senior residents (88.6\% vs. $83.3 \%, p=0.49$,Figure 2 . 
TABLE II Survey responses by medical and radiation oncology program directors and residents about current code status education

\begin{tabular}{|c|c|c|c|c|c|}
\hline \multirow[t]{2}{*}{ Survey item } & \multicolumn{2}{|c|}{$\begin{array}{l}\text { Program director } \\
\text { responses }[n(\%)]\end{array}$} & \multirow[t]{2}{*}{ Survey Item } & \multicolumn{2}{|c|}{$\begin{array}{c}\text { Resident responses } \\
{[n(\%)]}\end{array}$} \\
\hline & $\begin{array}{l}\text { Medical } \\
\text { oncology }\end{array}$ & $\begin{array}{l}\text { Radiation } \\
\text { oncology }\end{array}$ & & $\begin{array}{l}\text { Medical } \\
\text { oncology }\end{array}$ & $\begin{array}{l}\text { Radiation } \\
\text { oncology }\end{array}$ \\
\hline
\end{tabular}

Did you receive training in code status discussions before starting your current residency program?

$\begin{array}{lll}\text { Yes } & 20(54.1) & 28(48.3) \\ \text { No } & 17(45.9) & 30(51.7)\end{array}$

Does your postgraduate program curriculum currently include formal teaching on code status discussion skills for all trainees?

$\begin{array}{lll}\text { Yes } & 3(33.3) & 6(66.7) \\ \text { No } & 5(62.5) & 3(37.5)\end{array}$

By the end of your residency, will you have received any formal training in discussing code status with cancer patients?

$\begin{array}{lcc}\text { Yes } & 20(54.1) & 19(32.8) \\ \text { No } & 13(35.1) & 16(27.6) \\ \text { Not sure } & 4(10.8) & 22(37.9)\end{array}$

Does your postgraduate program curriculum currently include informal teaching on code status discussion skills for all trainees in oncology?

$\begin{array}{lll}\text { Yes } & 8(88.9) & 6(75.0) \\ \text { No } & 1(11.1) & 2(25.0)\end{array}$

Does your postgraduate residency training program currently evaluate competence in code status discussion skills for all trainees?

$\begin{array}{lll}\text { Yes } & 3(33.3) & 4(50.0) \\ \text { No } & 6(66.7) & 4(50.0)\end{array}$

Have you received any formal evaluation

of your ability to lead a code status

discussion in your residency?

$\mathrm{N}$

$6(66.7) \quad 4(50.0)$

$\begin{array}{lcc}\text { Yes } & 14(37.8) & 5(8.6) \\ \text { No } & 23(62.2) & 52(89.7) \\ \text { Not sure } & 0(0) & 1(1.7)\end{array}$

Do you expect trainees to be fully competent in code status discussion before starting your program?

$$
\begin{aligned}
& \text { Yes } \\
& \text { No }
\end{aligned}
$$

5 (55.6) $\quad 3(37.5)$

$4(44.4) \quad 5(62.5)$
It is expected that I am already competent in this skill before starting my current residency program?
Yes
$16(43.2) \quad 28(48.3)$
No

In your program, is there a mechanism to identify a learner with a weakness in discussing code status?

$\begin{array}{lll}\text { Yes } & 1(11.1) & 4(50.0) \\ \text { No } & 8(88.9) & 4(50.0)\end{array}$

If you identify a learner with a weakness in this area, does your residency training program offer any mechanisms for remediation?

$\begin{array}{lll}\text { Yes } & 4(44.4) & 2(25.0) \\ \text { No } & 5(55.6) & 6(75.0)\end{array}$

\section{Barriers to Teaching}

Respondents were asked to report perceived barriers to teaching on this topic. The most commonly identified barriers among PDs and residents included lack of time, lack of teaching and evaluation resources, and lack of interest among staff preceptors to offer training in this area (Table III). Regarding the disengagement of preceptors, one resident commented, "Staff remove themselves from this conversation, so teaching does not happen organically."

Trainees commonly identified the expectation of competence before program entry as a barrier to education. This was reported similarly by medical and radiation oncology residents even though medical oncology training starts in the fourth postgraduate year and radiation oncology training is entered directly from undergraduate medical

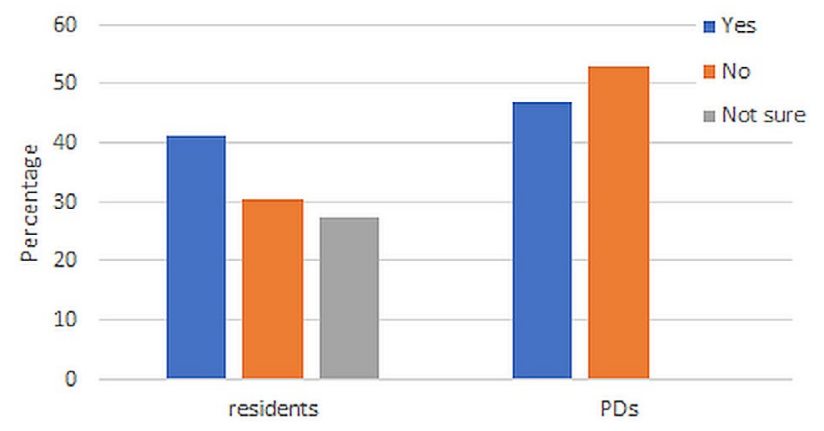

FIGURE 1 Responses by program directors (PDS) and residents in oncology training programs to the question "Does your program provide formal training on code status communication?" 


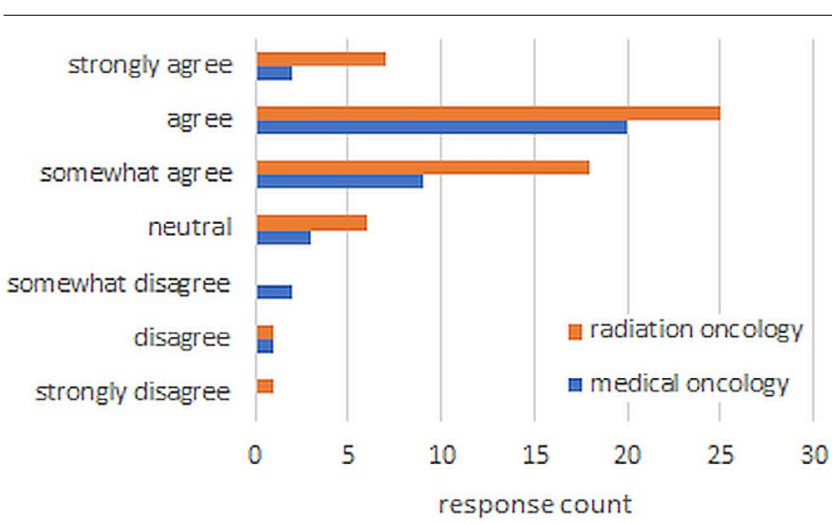

FIGURE 2 Responses by residents to the statement "In my residency program, I would benefit from having more formal teaching on code status discussions with cancer patients," by discipline.

school. The majority of PDs (82.3\%) endorsed the need for new teaching tools. New resources of greatest interest to PDs included an electronic module, a validated communication framework, and a workshop curriculum.

\section{Patterns of Practice Among Trainees in Clinical Encounters}

Trainees were asked about their experiences carrying out code status discussions with patients with cancer during oncology residency. Resident-led code status discussions were reported to occur more frequently in an acute-care setting (emergency room, hospital ward, or intensive care unit) than in an ambulatory care setting. A total of $84.2 \%$ of residents reported leading such discussions in clinic no more than once per month, whereas $60 \%$ reported that such discussions occurred in acute-care locations at least once per week (Figure 3). About three quarters (72.6\%) of residents reported that code status discussions occur always or most often during on-call rather than workday hours, suggesting that most conversations are not directly supervised by a staff preceptor. When residents were asked about advising patients on code status, commonly identified barriers included difficulty giving advice on this topic when meeting a patient for the first time $(60 \%)$, patients and family members unwilling to discuss the topic (43.2\%), and difficulty estimating prognosis (28.4\%).

\section{DISCUSSION}

Code status communication is an important component of quality EOL care for terminally ill patients with cancer. Oncology residency training is an opportunity to develop skills to lead such critical conversations. In this cross-sectional study of Canadian medical and radiation oncology PDs and residents, a gap in medical education on code status communication was identified. A substantial portion of residents never received formal training on this topic before entering an oncology program (even among medical oncology trainees who already completed 3 years of internal medicine residency). Furthermore, residents and PDs reported that this topic is not commonly addressed in formal oncology curricula. To our knowledge, no other
TABLE III Barriers to teaching communication skills for code status discussions in oncology

\begin{tabular}{llc}
\hline \multicolumn{1}{|c}{ Barrier identified } & $\begin{array}{c}\text { Program } \\
\text { directors } \\
\mathbf{( \% )}\end{array}$ & $\begin{array}{c}\text { Residents } \\
\mathbf{( \% )}\end{array}$ \\
\hline Lack of time & 29.4 & 38.9 \\
\hline Lack of teaching resources & 64.7 & 52.6 \\
\hline Lack of evaluation resources & 76.5 & 29.5 \\
\hline $\begin{array}{l}\text { Limited interest among staff preceptors } \\
\text { Expectation of competence before }\end{array}$ & 35.3 & 26.3 \\
\hline $\begin{array}{l}\text { oncology program entry } \\
\text { Limited interest among trainees }\end{array}$ & - & 46.3 \\
\hline $\begin{array}{l}\text { Preceptors lack confidence in leading } \\
\text { code status discussions }\end{array}$ & 5.9 & 22.1 \\
\hline \begin{tabular}{l} 
This competency is too hard to teach \\
\hline
\end{tabular} & 0 & 8.4 \\
\hline
\end{tabular}

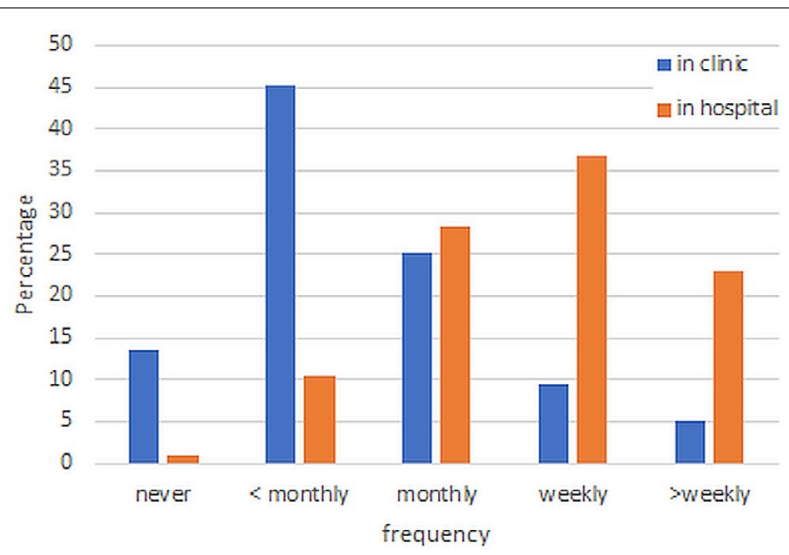

FIGURE 3 Responses by residents about the frequency of resident-led code status discussion with patients with cancer, by care setting.

studies have characterized current communication training on code status within oncology residency programs; yet similar findings have been described in other fields ${ }^{3,16}$. Despite trainees frequently leading critical code status conversations, observation and feedback are uncommon on medical teaching wards ${ }^{16}$. Surveys of graduating residents in family practice and those rotating through critical care have shown a substantial lack of training for EOL decision-making ${ }^{3}$. Our results show that many residents perceive an expectation from preceptors that they should have baseline competence in this area, and this expectation is also reported by many PDs. Again, this is in keeping with findings of studies in which residents with no prior training for EOL decision-making report a lack of support and role modelling for such encounters in the critical care setting ${ }^{17}$. It is concerning to find that despite limited prior training, formal teaching and evaluation of code status discussion is scarce during oncology residency, and mechanisms to identify learners with weakness in this area or to offer remediation are uncommon.

Despite the apparent lack of formal training, the importance of competence in discussing code status was 
strongly endorsed by PDs and residents alike. Moreover, residents indicated an interest in additional training to develop this skill. There is a gap between support for education on this topic and current practice, in which formal training in oncology curricula is lacking. Canadian oncology residency programs are transitioning to a competency-based curriculum and an evaluation format requiring repeated assessment of entrustable professional activities, including EOL communication tasks. Thus, education on this topic will be essential for residents to successfully advance through training.

Barriers to education on EOL care have been previously identified. A survey of residents and medical faculty across the United States showed that a substantial portion of respondents felt unprepared to teach EOL topics ${ }^{18}$. When medical school deans were surveyed, barriers to education on EOL care included lack of time in curricula, lack of qualified educators, and lack of leadership among faculty ${ }^{19}$. We found additional important barriers influencing code status communication training in oncology, including a lack of teaching and evaluation tools. Program directors support the need to develop new resources, including novel Web-based tools. This will inform ongoing work to design and validate educational resources on this topic that can be used in competency-based curricula for postgraduate oncology trainees.

Trainees report that resident-led code status discussions occur frequently but are most likely to occur in the acute-care setting during after-hours coverage. Residents typically provide on-call service in academic health care institutions, which includes admitting patients to hospital through the emergency department and managing patients admitted to oncology wards whose condition requires assessment after hours. Patient interactions generally are not directly supervised by staff preceptors in these circumstances. The implications of resident-led code status discussions occurring after hours are 2-fold. First, although observation and feedback were identified as teaching tools, it is likely that most code status conversations led by residents are not observed, and the trainee most often receives no feedback on his or her performance. This was borne out in responses, where only $20 \%$ of trainees indicated receiving evaluation on this skill. Learning opportunities are missed as a consequence of carrying out code status conversations during on-call coverage. Second, the code status discussion that occurs at the time of hospital admission could influence the aggressiveness of care throughout the subsequent hospital stay. For patients with cancer admitted to hospital near EOL, the decision to pursue aggressive management could potentially lead to ICU admission, an indicator of suboptimal EOL care for terminally ill patients ${ }^{20}$. Residents often fail to explore a patient's values with respect to EOL care or to offer a recommendation for care ${ }^{1,4}$. Unwanted invasive intervention might be more likely as a result of poor communication. Resident-identified barriers to advising on code status (such as difficulty with estimation of prognosis), and the patient-important ramifications of code status discussions at times of hospitalization highlight the importance of skill building and education on this topic.
This study has several strengths. The response rate was high among both PDs and trainees. Both oncology disciplines and all postgraduate training levels were represented among respondents. Thus, the results of this cross-sectional study are more likely to accurately reflect current educational practices in Canada. There are some limitations to this study. With regard to survey validation, our pilot group included 10 individuals. We sampled content experts, educators, and trainees. While this was a small sample, given the target population was fairly homogeneous with regard to education and professional context, this may have been adequate for validation. To quantify educational practices within oncology training, residents were asked the following question: "By the end of your residency, will you have received any formal training in discussing code status with cancer patients?" Early residents may not have knowledge of planned educational activities. However, PDs were asked similar questions and have knowledge of the entire curriculum for their programs. For privacy, information regarding a respondent's specific institution was not collected. Understanding variation in training opportunities as a function of a specific program was therefore not possible. It is likely that more trainee responses were collected from programs with the greatest enrolment, and so results are likely to be influenced most by the educational practices within the largest training programs. Additionally, survey responses might be influenced by social desirability bias, potentially leading to over estimation of desire for enhanced education on code status communication. This study was carried out only in Canada; however, based on similarities in oncology training in the United States and other jurisdictions, results are likely generalizable ${ }^{21-23}$.

\section{CONCLUSIONS}

Code status communication is an important skill for clinicians in oncology, and yet we found that teaching and evaluation are limited in this area for current oncology residents in Canada. Residents and PDs support the need for increased teaching on this topic, and current barriers to education have been identified. The results of this study provide a foundation for developing new educational resources to fill a gap in training for oncology residents. We are now developing a communication framework, an educational workshop, and an online module for use in oncology residency programs. Our findings are timely given that the ongoing transition to competency-based curricula in Canadian postgraduate medical education creates an opportunity to standardize teaching and evaluation practices relating to code status communication training.

\section{ACKNOWLEDGMENTS}

Prior presentation: Levine O, McConnell M, Dhesy B, Brouwers M, Mukherjee S. Code status communication training in Canadian postgraduate oncology programs: a needs assessment survey [poster]. 2017 ASCO Palliative and Supportive Care in Oncology Symposium; San Diego, CA, U.S.A.; October 2017.

\section{CONFLICT OF INTEREST DISCLOSURES}

We have read and understood Current Oncology's policy on disclosing conflicts of interest, and we declare that we have none. 


\section{AUTHOR AFFILIATIONS}

*Department of Oncology, McMaster University, Hamilton, ${ }^{\dagger}$ Department of Innovation in Medical Education, University of Ottawa, Ottawa, ${ }^{\ddagger}$ Department of Anesthesiology and Pain Medicine, University of Ottawa, Ottawa, and ${ }^{\S}$ School of Epidemiology and Public Health, University of Ottawa, Ottawa, ON.

\section{REFERENCES}

1. Smith AK, Ries AP, Zhang B, Tulsky JA, Prigerson HG, Block SD. Resident approaches to advance care planning on the day of hospital admission. Arch Intern Med 2006;166:1597-602.

2. Calam B, Far S, Andrew R. Discussions of "code status" on a family practice teaching ward: what barriers do family physicians face? CMAJ 2000;163:1255-9.

3. Gorman TE, Ahern SP, Wiseman J, SkrobikY. Residents' endof-life decision making with adult hospitalized patients: a review of the literature. Acad Med 2005;80:622-33.

4. Deep KS, Griffith $\mathrm{CH}$, Wilson JF. Communication and decision making about life-sustaining treatment: examining the experiences of resident physicians and seriously-ill hospitalized patients. J Gen Intern Med 2008;23:1877-82.

5. Loertscher LL, Beckman TJ, Cha SS, Reed DA. Code status discussions: agreement between internal medicine residents and hospitalized patients. Teach Learn Med 2010;22:251-6.

6. Deep KS, Griffith CH, Wilson JF. Discussing preferences for cardiopulmonary resuscitation: what do resident physicians and their hospitalized patients think was decided? Patient Educ Couns 2008;72:20-5.

7. Alexander SC, Keitz SA, Sloane R, Tulsky JA. A controlled trial of a short course to improve residents' communication with patients at the end of life. Acad Med 2006;81:1008-12.

8. Szmuilowicz E, el-Jawahri A, Chiappetta L, Kamdar M, Block S. Improving residents' end-of-life communication skills with a short retreat: a randomized controlled trial. $J$ Palliat Med 2010;13:439-52.

9. Back AL, Arnold RM, Baile WF, et al. Efficacy of communication skills training for giving bad news and discussing transitions to palliative care. Arch Intern Med 2007;167:453-60.

10. Streiner D, Norman G, Cairney J. Health Measurement Scales: A Practical Guide to Their Development and Use. 5th ed. New York, NY: Oxford University Press; 2015.

11. Buss MK, Alexander GC, Switzer GE, Arnold RM. Assessing competence of residents to discuss end-of-life issues. JPalliat Med 2005;8:363-71.
12. Miller GA. The magical number seven plus or minus two: some limits on our capacity for processing information. Psychol Rev 1956;63:81-97.

13. Binder AF, Huang GC, Buss MK. Uninformed consent: do medicine residents lack the proper framework for code status discussions? J Hosp Med 2016;11:111-16.

14. CaRMS. R-1 Match Reports. 2017. [Available online at: https:// www.carms.ca/en/data-and-reports/r-1/; cited 20 July 2017]

15. CaRMS. MSM Reports. 2017. [Available online at: https://www. carms.ca/en/data-and-reports/msm/. Published 2017; cited 20 July 2017]

16. Tulsky JA, Chesney MA, Lo B. See one, do one, teach one? House staff experience discussing do-not-resuscitate orders. Arch Intern Med 1996;156:1285-9.

17. Stevens L, Cook D, Guyatt G, Griffith L, Walter S, McMullin J. Education, ethics, and end-of-life decisions in the intensive care unit. Crit Care Med 2002;30:290-6.

18. Sullivan AM, Lakoma MD, Block SD. The status of medical education in end-of-life care: a national report. J Gen Intern Med 2003;18:685-95.

19. Sullivan AM, Warren AG, Lakoma MD, Liaw KR, Hwang D, Block SD. End-of-life care in the curriculum: a national study of medical education deans. Acad Med 2004;79:760-8.

20. Earle CC, Park ER, Lai B, Weeks JC, Ayanian JZ, Block S. Identifying potential indicators of the quality of end-of-life cancer care from administrative data. JClin Oncol 2003;21: 1133-8.

21. Information by Discipline. Royal College. 2020. [Available online at: http://www.royalcollege.ca/rcsite/ibd-search-e; cited 28 May 2020]

22. ACGME Program Requirements for Graduate MedicalEducation in Hematology and Medical Oncology (Subspecialty of Internal Medicine). ACGME. Common Program Requirements Web site. 2019. [Available online at: https://www.acgme.org/Portals/0/ PFAssets/ProgramRequirements/155_HematologyAnd MedicalOncology_2019.pdf?ver=2019-08-01-123253-047; cited 28 May 2020]

23. ACGME Program Requirements for Graduate Medical Education in Radiation Oncology. ACGME. Common Program Requirements Web site. 2020. [Available online at: https://www. acgme.org/Portals/0/PFAssets/ProgramRequirements/430 RadiationOncology_2020.pdf?ver $=2020-02-20-135340-140$; cited 28 May 2020] 